\title{
Training in endocrine surgery
}

\section{Oliver Gimm ${ }^{1}$ (D) $\cdot$ Marcin Barczyński $^{2}$ (D) $\cdot$ Radu Mihai $^{3}$ (D) $\cdot$ Marco Raffaelli $^{4,5}$ (D)}

Received: 24 July 2019 / Accepted: 20 September 2019/Published online: 7 November 2019

(C) The Author(s) 2019

\begin{abstract}
Background/purpose In Europe, the Division of Endocrine Surgery (DES) determines the number of operations (thyroid, neck dissection, parathyroids, adrenals, neuroendocrine tumors of the gastro-entero-pancreatic tract (GEP-NETs)) to be required for the European Board of Surgery Qualification in (neck) endocrine surgery. However, it is the national surgical boards that determine how surgical training is delivered in their respective countries. There is a lack of knowledge on the current situation concerning the training of surgical residents and fellows with regard to (neck) endocrine surgery in Europe.

Methods A survey was sent out to all 28 current national delegates of the DES. One questionnaire was addressing the training of surgical residents while the other was addressing the training of fellows in endocrine surgery. Particular focus was put on the numbers of operations considered appropriate.

Results For most of the operations, the overall number as defined by national surgical boards matched quite well the views of the national delegates even though differences exist between countries. In addition, the current numbers required for the EBSQ exam are well within this range for thyroid and parathyroid procedures but below for neck dissections as well as operations on the adrenals and GEP-NETs.

Conclusions Training in endocrine surgery should be performed in units that perform a minimum of 100 thyroid, 50 parathyroid, 15 adrenal, and/or 10 GEP-NET operations yearly. Fellows should be expected to have been the performing surgeon of a minimum of 50 thyroid operations, 10 (central or lateral) lymph node dissections, 15 parathyroid, 5 adrenal, and 5 GEP-NET operations.
\end{abstract}

Keywords Training $\cdot$ Resident $\cdot$ Fellow $\cdot$ Endocrine $\cdot$ Surgery

\section{Introduction}

Endocrine surgery is a subspecialty focusing on the surgical management of various diseases of the endocrine glands, including the thyroid gland, the parathyroid glands, the adrenal glands, and neuroendocrine tumors (NET) of the gastrointestinal tract and pancreas. These conditions are selectively managed by general surgeons, upper and lower gastrointestinal

Oliver Gimm

oliver.gimm@liu.se

Marcin Barczyński

marcin.barczynski@uj.edu.pl

Radu Mihai

radumihai@doctors.org.uk

Marco Raffaelli

marco.raffaelli@unicatt.it

1 Department of Surgery and Department of Clinical and Experimental Medicine (IKE), Linköping University, 58183 Linköping, Sweden surgeons, surgical oncologists, otolaryngologists, head and neck surgeons, and urologists depending on their surgical training backgrounds, professional interests, and referral patterns reflecting the local healthcare environment.

Training of surgical trainees has always been challenging and endocrine surgery is no exception. During residency, surgical trainees are confronted with a variety of different surgical procedures in order to become a surgical specialist. Following

2 Department of Endocrine Surgery, Third Chair of Surgery, Jagiellonian University Medical College, 37 Prądnicka Street, 31-202 Kraków, Poland

3 Department of Endocrine Surgery, Churchill Cancer Centre, Oxford University Hospital NHS Foundation Trust, Oxford OX3 7DU, United Kingdom

4 U.O. Chirurgia Endocrina e Metabolica, Fondazione Policlinico Universitario A. Gemelli IRCCS, Rome, Italy

5 Istituto di Semeiotica Chirurgica, Università Cattolica del Sacro Cuore, Rome, Italy 
residency, many surgical specialists decide to undertake a fellowship period in order to develop a subspecialty expertise, for example in endocrine surgery. While surgical residents are required to learn the basics of many surgical procedures, fellows are required to acquire a much more profound knowledge on (almost) every surgical aspect of their chosen subspecialty. Logically, fellows in endocrine surgery have to be confronted with many more cases than surgical residents.

In order to ensure that the training has reached the required level of knowledge and skills, standardized examinations are mandatory. In Europe, the Division of Endocrine Surgery (DES) is responsible for organizing such standardized examinations in endocrine surgery on behalf of the Section of Surgery of the European Union of Medical Specialist (UEMS). Successful candidates get a European Board of Surgery Qualification (EBSQ) certificate. The DES issues EBSQ certificates in neck endocrine surgery (i.e., thyroid gland and parathyroid gland surgery and knowledge of the underlying diseases) or endocrine surgery (including even the adrenal glands and NETs of the gastro-entero-pancreatic (GEP) tract). As of May 16, 2019, 108 surgeons had successfully passed the EBSQ examination in endocrine surgery and 54 surgeons/otolaryngology doctors had successfully passed the counterpart in neck endocrine surgery. Successful candidates are considered fellows of the DES and entitled to bear the title Fellow of the European Board of Surgery (FEBSendocrine surgery or FEBS - neck endocrine surgery).

The DES has an executive committee that is elected by national delegates. Currently, the DES has national delegates from 28 countries. These delegates are also the national delegates of the European Society of Endocrine Surgeons (ESES). The minimum number of operations required to be eligible for the EBSQ exam in (neck) endocrine surgery was determined by the national delegates before the first examination took place in 2003 (Table 1). Though the DES determines the number of operations to be required for the exam in (neck) endocrine surgery, it is the European national surgical boards that determine how surgical training is delivered in their respective countries.

So far, however, the requirements set out by the European national surgical boards with regard to endocrine surgery have not been investigated. In May 2019, the ESES organized the 8th biennial conference with the topic "Volume outcomes and quality in endocrine surgery." One working group was tasked to evaluate the current situation on the training of general surgery/otolaryngology residents in endocrine surgery and of endocrine surgery fellows. The members of the working group are the authors of this manuscript.

\section{Material and methods}

During October and November 2018, we performed a survey by sending out two questionnaires to all 28 current national
Table 1 Currently (May 2019) recommended minimal operative experience to be eligible for the European Board of Surgery Qualification in endocrine and neck endocrine surgery as defined by the Division of Endocrine Surgery, UEMS

\begin{tabular}{lll}
\hline Operations & Performed & Assisted \\
\hline Thyroid resections $^{\S}$ & & \\
Recurrent thyroid operation $^{\S}$ & 50 & 50 \\
Central compartmental lymph node clearance $^{\S}$ & 2 & 5 \\
Lateral compartment lymph node clearance $^{\S}$ & 2 & 15 \\
Parathyroidectomy in HPT $^{\S}$ & $15^{*}$ & $20^{*}$ \\
Adrenalectomy $^{\#}$ & 2 & 10 \\
Resection for NET of the GI tract $^{\#}$ & 2 & 5 \\
\hline
\end{tabular}

*At least 10 bilateral explorations demanded

${ }^{\S}$ Required for both the exam in endocrine and neck endocrine surgery

${ }^{\#}$ Required only for the exam in endocrine surgery

delegates of the DES/ESES. One questionnaire was addressing the training of surgical residents while the other was addressing the training of fellows in endocrine surgery. The questionnaires were also sent to a few non-European endocrine surgeons. Their responses are briefly addressed in the discussion.

The national delegates were asked regarding the current minimum numbers of operations deemed necessary for the completion of training in their respective countries and concerning the numbers of operations they themselves considered to be appropriate for being competent with regard to independent practice in surgery of the thyroid gland including neck dissections, the parathyroid glands, the adrenal glands, and NETs of the gastro-entero-pancreatic tract. In general, we distinguished between operations participated in as the performing (main) surgeon and as the assisting surgeon. Additional questions were asked about the structure/content of the existing postgraduate examinations.

In preparing this manuscript, the authors also searched the PubMed database by using various combinations of the following search terms: surgery, training, resident/residency, fellow(ship), thyroid(ectomy), parathyroid(ectomy), adrenal(ectomy), neuroendocrine, gastric, intestine, pancreas, and outcomes.

\section{Results}

\section{Personal views of the national delegates and existing examinations}

\section{Surgical residents}

A total of 24 national delegates ( $86 \%$ of 28 ) of the DES responded to the questionnaire on the training of surgical residents. Only half of the responders considered that 20 or more endocrine surgical procedures operations should be 
mandatory (Table 2). At the low end of this spectrum, one respondent indicated that 5 or less performed procedures would be acceptable.

A final written exam followed by an oral exam at the end of surgical residency is mandatory in 10 European countries. An oral exam only is mandatory in another 10 European countries whereas no mandatory exam exists in four European countries. A practical exam (e.g., OSCE) is organized in 12 European countries and a three-stage exam (written, oral, and practical) is mandatory in six European countries.

\section{Fellows in endocrine surgery}

Sixteen national delegates (57\% of 28 ) replied to the questionnaire on the training of fellows in endocrine surgery. Only three respondents considered that 200 or more endocrine surgical procedures should be performed during fellowship training in endocrine surgery, whereas 3 respondents considered 100-199 performed procedures to be sufficient. Three respondents agreed that 50-99 performed procedures would be a minimum (Table 2). Only 1 respondent indicated that less than 50 procedures performed would be acceptable, whereas 6 respondents skipped to answer this question. A written exam followed by an oral exam at the end of the fellowship in endocrine surgery is mandatory in three European countries, and an oral exam only is mandatory in one European country, whereas no obligatory exam exists in 12 European countries. A practical exam (e.g., OSCE) is organized in only one European country and it is a part of a three-stage exam (written, oral, and practical).

Table 2 Recommended minimal operative experience of endocrine surgical operations for surgical residents and fellows in endocrine surgery as defined by the national delegates of the Division of Endocrine Surgery/European Society of Endocrine Surgeons

\begin{tabular}{ll}
\hline $\begin{array}{l}\text { Number of minimal operations } \\
\text { recommended }\end{array}$ & $\begin{array}{l}\text { Number of national } \\
\text { delegates agreeing } \\
\text { on this number }\end{array}$ \\
\hline $\begin{array}{l}\text { Surgical residents } \\
\geq 50\end{array}$ & 4 \\
$20-49$ & 10 \\
$10-19$ & 3 \\
$5-9$ & 2 \\
$<5$ & 1 \\
Fellows in endocrine surgery & \\
$\geq 200$ & 3 \\
$100-199$ & 3 \\
$50-99$ & 3 \\
$<50$ & 1 \\
\hline
\end{tabular}

Training in thyroid gland surgery and neck dissection

\section{Survey results}

Programs for surgical residents contained thyroid procedures in the majority $(n=22)$ but not all European countries $(n=2)$. The minimum number of total/near-total thyroidectomies to be performed/assisted during residency varied between 0 and 40 (median 0.5)/0 and 50 (median 0) and these values were far below the values expected to be sufficient from the national delegates' perspective: 0-50 (median 10) and 0-50 (median 20 ), respectively. The minimum number of hemithyroidectomies (or thyroid resections) to be performed/assisted during residency ranged from 0 to 50 (median 0$) / 0$ to 50 (median 0 ) and these values were also below the values expected to be required from the national delegates' perspective: 0-50 (median 15) and 0-50 (median 20), respectively. The minimum number of central lymph nodes dissections to be performed/ assisted varied from 0 to 20 (median 0 ) and 0 to 20 (median 0 ), respectively. The national delegates' expectations were slightly higher in this regard: 0-20 (median 5) and 0-50 (median 10), respectively. The minimum number of lateral lymph nodes dissections to be performed/assisted during surgical residency ranged from 0 to 10 (median 0 ) and 0 to 20 (median 0), respectively. The national delegates' expectations were relatively consistent with the current minimum requirement for performed operations with 0-10 (median 2) but much higher for assisted lateral neck dissections with 0 20 (median 5).

With regard to fellows (Fig. 1), our survey revealed that the programs for fellowships in endocrine surgery contained thyroid procedures in all European countries which offer some form of fellowship in this area. The minimum numbers of total/near-total thyroidectomies to be performed/assisted during fellowship varied from 20 to 30 (median 30)/0 to 100 (median 30) and these values were somewhat below the values expected to be optimal from the national delegates' perspective with 10-60 (median 30) and 20-100 (median 50), respectively. The minimum numbers of hemithyroidectomies (or thyroid resections) to be performed/ assisted during fellowship varied from 20 to 40 (median 30)/10 to 50 (median 25) and theses values were also below the values expected to be optimal from the national delegates' perspective with 20-60 (median 40) and 20-100 (median 50), respectively. The minimum numbers of central lymph node dissections to be performed/assisted varied from 5 to 20 (median 10)/10 to 30 (median 20), and the national delegates' expectations were very similar in this regard with 5-30 (median 10) and 10-30 (median 20 ), respectively. The minimum numbers of lateral lymph nodes dissections to be performed/assisted during fellowship varied from 10 to 30 (median 20)/5 to 50 (median 10), and national delegates' expectations were very similar for both performed operations with 5-30 (median 15) and assisted lateral neck dissections with 5-50 (median 15). 


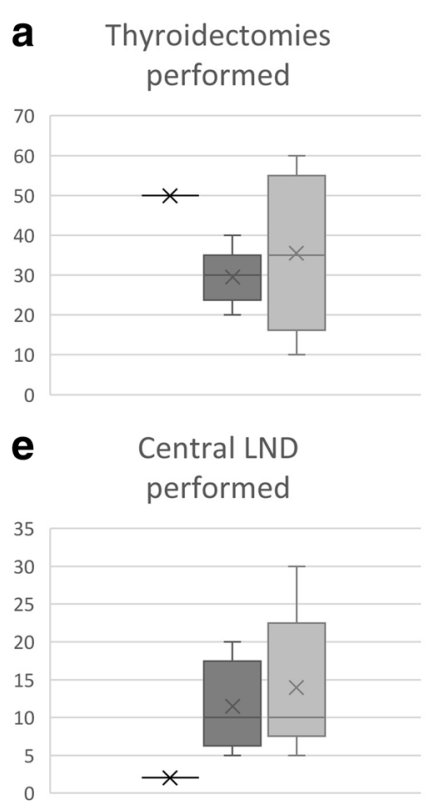

\section{i Adrenalectomies performed}

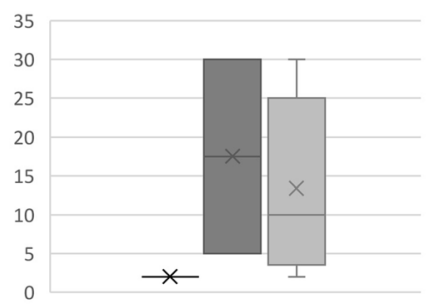

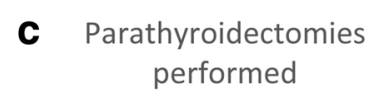

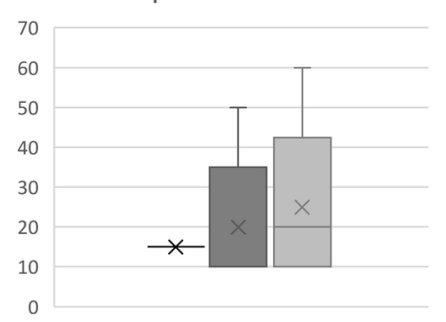

$\mathbf{9}$
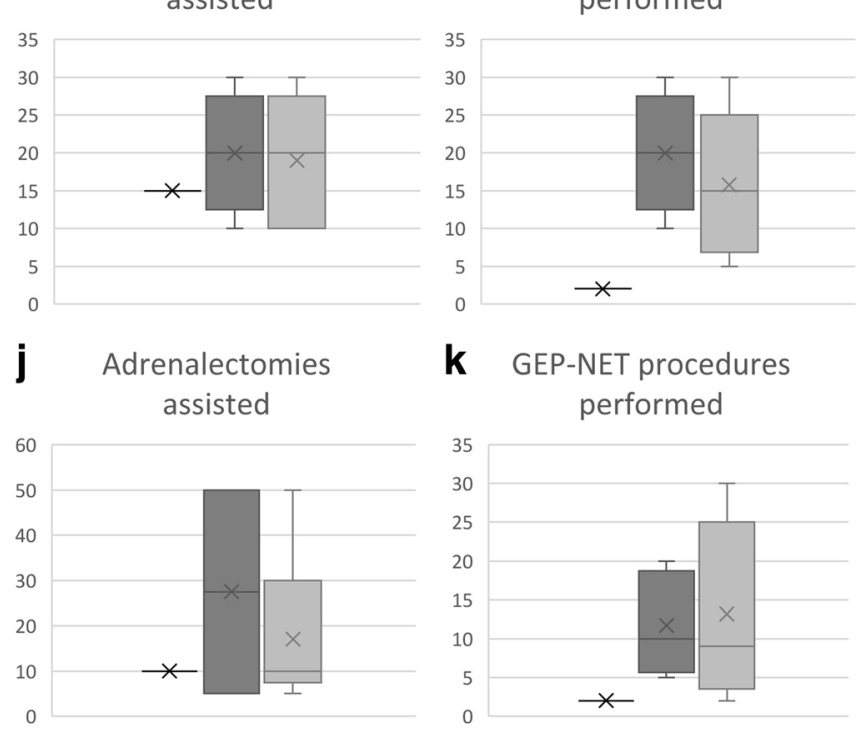

\section{k GEP-NET procedures performed}

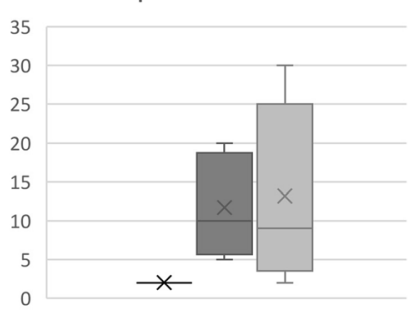

Fig. 1 Number of operations considered appropriate for fellows in endocrine surgery regarding thyroidectomies $(\mathbf{a}, \mathbf{b})$, parathyroidectomies $(\mathbf{c}, \mathbf{d})$, central $(\mathbf{e}, \mathbf{f})$ and lateral $(\mathbf{g}, \mathbf{h})$ lymph node dissections (LND), adrenalectomies (i, j) and various surgical procedures concerning gastro-entero-pancreatic neuroendocrine tumors (GEP-NET) (k, l). Horizontal black line, current (May 2019)

\section{Literature regarding training in thyroid surgery and neck dissection}

The current training of general surgical residents with regard to thyroid and other types of endocrine operations is highly variable, which may contribute to increased complication rates and number of reoperations [1]. The mean minimum number of thyroid operations to be done during surgical residency as shown by this survey was 5 performed and 13 assisted procedures, and these values were two-fold lower than what was recommended by the national delegates on average. This issue raises the question if a general surgeon with no special interest in thyroid surgery has received enough exposure during residency to be able to perform a total thyroidectomy safely.

Total thyroidectomy is an operation that always engenders controversy related to injury of the recurrent laryngeal nerves and the parathyroid glands. It has been shown that surgeons who have completed a well-designed training program and who have become proficient in total thyroidectomy as trainees
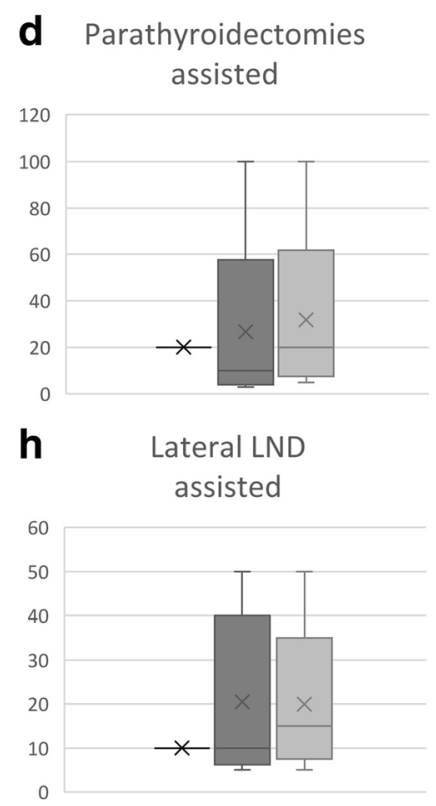

I GEP-NET procedures

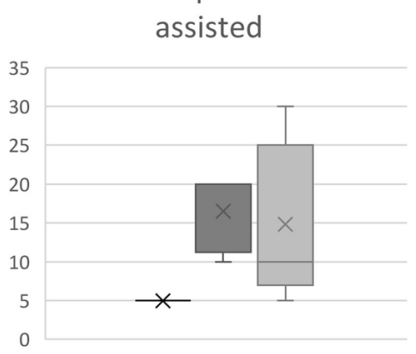

requirements as defined by the Division of Endocrine Surgery. Dark gray boxplot, current requirements as defined by European national surgical boards. Bright gray boxplot, recommended numbers by European national delegates

will remain proficient despite practicing in a provincial center [2]. Achieving a low morbidity rate demands meticulous attention to operative technique and anatomical details [2].

Interesting insight into this issue was recently provided by Phitayacorn et al. who published an expert consensus of general surgery residents' proficiency concerning common endocrine operations. In this study, members of the American Association of Endocrine Surgeons (AAES) were surveyed about their opinions on resident proficiency with regard to common endocrine operations [3]. A total of $92 \%$ of the respondents operated with residents. On average, they believed that most of the steps of a total thyroidectomy for benign disease could be performed by a postgraduate year 4 surgery resident. Specific steps that were considered to require more training included decisions to divide the strap muscles or leaving a drain. Approximately $66 \%$ of the respondents felt that a postgraduate final-year surgery resident could independently perform a total thyroidectomy for benign disease but only $45 \%$ felt similarly for malignant thyroid disease. The annual endocrine volume of the respondents did not correlate with the 
beliefs concerning the residents' autonomy. There was general agreement that a postgraduate final-year resident may not be proficient in advanced endocrine operations. Nevertheless, it was also felt that opportunities exist to improve the training for graduates that anticipate performing endocrine operations routinely $[3,4]$. For more data on pertinent training issues on thyroid surgery see Table 3 .

The literature on the training of neck dissection is sparse. According to one report, surgical residents perform on average less than 2 neck dissections. Fellows in endocrine surgery perform more neck dissections but the numbers of such procedures vary between about 6 and 15 [9, 13]. According to one report, 12 neck dissections are considered appropriate to achieve the required competence [13].

\section{Training in parathyroid gland surgery}

\section{Survey results}

Only a minority of the European surgical residency programs include parathyroid procedures during the training of graduating residents. The numbers of procedures assisted/performed varied widely ranging from 0 to 40 for assisted focused parathyroidectomy (FP) (median 0), from 0 to 30 for performed FP (median 0 ), from 0 to 10 for assisted bilateral neck exploration (BNE) (median 0 ), and from 0 to 5 for performed BNE (median 0 ). This was in contrast with the personal views of the respondents. Most of them considered that graduating surgeons should assist and perform a higher minimum number of FP (19 out of 24 (79.2\%) and 17 out of 24 (70.8\%), respectively) and BNE (18 out of 24 (75.0\%) and 15 out of 24 (62.5\%), respectively). In the opinion of the respondents, the minimum number of parathyroid procedures that should be assisted and performed during residency varied widely ranging from 0 to 40 for assisted FP (median 10), from 0 to 30 for performed FP (median 10), from 0 to 30 for assisted BNE (median 7.5), and from 0 to 30 for performed BNE (median 5).

For the available fellowship programs, national delegates reported a wide range of experience in parathyroid surgery. The number of procedures assisted/performed varied widely ranging from 3 to 100 for assisted FP (median 7.5), from 10 to 50 for performed FP (median 20), and from 5 to 20 for assisted BNE (median 10), and were 10 for performed BNE (median 10). All the responding national delegates from countries in which there are no endocrine surgery fellowships programs available agreed that a post-residency training is needed to achieve the expected competency.

In the opinion of the respondents, the minimum number of parathyroid procedures that should be assisted and performed during an endocrine surgery fellowship varied widely ranging from 5 to 100 for assisted FP (median 20), from 10 to 60 for performed FP (median 25), from 10 to 30 for assisted BNE (median 20), and from 10 to 30 for performed BNE (median 15).

\section{Literature regarding training in parathyroid surgery}

Using the search terms "parathyroidectomy AND training," "parathyroidectomy AND residency," and "parathyroidectomy AND fellowship," 205 publications were identified on PubMed. However, only 12 of them were found to be relevant for this analysis $[3,5-7,9-14,18,21]$. The principal findings of the papers are summarized in Table 3 .

All the studies included in the analysis were evaluating surgical training of US general surgery/otolaryngology residency programs or US endocrine surgery fellowship programs. No English literature was found on the training of general surgery/otolaryngology residents with regard to parathyroid surgery outside the USA.

In the USA, the data of the Residency Review Committee (RRC) of the Accreditation Council for Graduate Medical Education (ACGME) showed that there was a gradual but significant increase of the average numbers of endocrine surgical procedures from 1986 to 2008, parathyroidectomies in particular, performed by graduating general surgery residents (mean 4.1 parathyroid procedures in 1986 versus 9.6 in 2015) [5-7, 9-11, 14] (Table 3). Data of ACGME accredited otolaryngology - head and neck — surgery residency programs over 20 years (1996-2015) showed that the numbers of parathyroidectomies performed by graduating residents have steadily grown from 1.8 in 1996 to 16.3 in 2015 (an $800 \%$ increase) [3,10, 14]. Zarebczan B. et al. [14] reported that most general surgery residents performed parathyroidectomies (and thyroidectomies) early during their training. Conversely, otolaryngology residents are performing most parathyroidectomies (and thyroidectomies) as chief residents (Table 3).

A recent survey conducted among AAES members reported that the respondents on average believe that all the steps of parathyroidectomy for a well-localized adenoma could be performed by a postgraduate 4-year surgery resident under direct supervision by an attending surgeon [3]. In addition, most of the respondents (79\%) reported that a postgraduate final-year resident from their institution could autonomously perform a parathyroidectomy in a patient with concordant imaging [3] (Table 3).

In the late 1900s, in residency programs with one or more endocrine surgeon(s) in the teaching faculty, the number of parathyroidectomies performed by graduating general surgery residents was significantly higher as opposed to residency programs where such competency was missing [6] (Table 3). In addition, it has been reported that graduated general surgeons who choose to continue training in endocrine surgery performed significantly more endocrine cases during residency than the average graduating surgical resident (26 versus 9) [13] (Table 3).

Data on fellows training are less accurate since even in the USA there is no database for recognized fellowships like that 
Table 3 Summary of relevant publications on training in endocrine surgery

$\begin{array}{ll}\text { Reference } & \begin{array}{l}\text { Publication } \\ \text { date }\end{array}\end{array}$

Harness et al. [5] 1995

During 8 academic years (1986-1994), the average number of thyroidectomies performed by resident graduating of US general surgery programs ranged from 10.3 to 12.6 (maximum from 52 to 102), with the most common number of thyroidectomies performed ranged from 7 to 10 per graduating resident.

For parathyroidectomy, the average ranged from 4.1 to 5.1, the maximum ranged from 25 to 60 , and the most common number performed was 2.

Prinz [6] 1996

Parsa et al. [7] 2000

Manolidis et al. [8] 2001

Sosa et al. [9] 2007

Terris et al. [10] 2007

Le et al. [11] 2008

Goldfarb et al. [12] 2010

Solorzano et al. 2010 [13]

Zarebczan et al.

2010

[14]
During the academic years 1994-1995, the number of endocrine procedures performed per resident of US general surgery programs increased. In particular, thyroidectomy $13.5 \pm 5.8$ (range 3-35), parathyroidectomy $6.1 \pm 3.4$ (range 1-48).

In residency programs with one or more endocrine surgeon(s) in the teaching faculty, the number of thyroidectomies ( $14.5 \pm 5.4$ vs $12.5 \pm 6.1)$ and parathyroidectomies $(7.3 \pm 3.7$ vs $4.9 \pm 2.5)$ was significantly higher.

The overall operative volume of US general surgery resident increased from 1991 to 1997. In particular, there was a $19.2 \%$ increase in the average number of thyroidectomies (14.2 vs 12.1$)$ and a $51.2 \%$ increase in the number of parathyroidectomies performed (6.1 vs 4.4).

The results of thyroid surgery performed by residents in training in an otolaryngology — head and neck — surgery program in a metropolitan public hospital, measured by rates of complications, length of hospitalization, and duration of surgery, are similar to those of faculty at a private hospital setting in groups of patients with very similar characteristics.

From 2001 to 2006, US graduating general surgery chief residents on average have performed $<30$ endocrine procedures (18 thyroidectomies, 8.6 parathyroidectomies, 1.8 adrenalectomies, 0.1 operations for neuroendocrine tumors of the pancreas, 1.5 neck dissections).

From 2003 to 2006, the average number of endocrine procedures during US endocrine surgery fellowship was 253 (range 107-445), including 127 thyroidectomies, 90 parathyroidectomies, 15 neck dissections, 15 adrenalectomies, and 3.0 pancreas procedures.

There was a gradual increase in the mean number of parathyroidectomies performed by US general surgery residents from 6.0 in 1996 to a peak of 9.2 in 2004; this volume has begun to decline in 2005 (to 8.5). During the same timeframe, the mean number of parathyroidectomies performed by OHNS residents rose sharply and steadily from 1.8 in 1996 to 10.9 in 2005.

Between 1995 and 2004, there was a gradual increase in the mean number of endocrine surgical procedures by US general surgery residents (thyroidectomies from 13.2 to 18.2 , parathyroidectomies from 5.6 to 9.2, adrenalectomies from 1.2 to 1.7 ) with the exception of endocrine pancreas resection (from 0.2 to 0.1 ) and other major endocrine procedures $(0.1$ to 0.1$)$

US fellowship programs showed significant differences in the number of endocrine operative cases performed at each program ranging from 27 to 732 (thyroidectomies 15 to 500, parathyroidectomies 10 to 500 , adrenalectomies 1 to 75 , endocrine pancreas 1 to 100 , GI endocrine 0 to 40 ).

Between 2005 and 2008, at hospitals participating in the National Surgical Quality Improvement Program (NSQIP) of the American College of Surgeons, senior residents assisted in 36.5\% of 29,161 endocrine operations (51.7\% of 1781 adrenalectomies, $34.9 \%$ of 18,279 thyroidectomies and $36.7 \%$ of 9101 parathyroidectomies). Junior residents assisted in $30.6 \%$ of the total cases (11.3\% of adrenalectomies, $31.3 \%$ of thyroidectomies, and $32.9 \%$ of parathyroidectomies). Fellows assisted in $6.6 \%$ of the total cases (18.3\% of adrenalectomies, $4.7 \%$ of thyroidectomies, and $8.2 \%$ of parathyroidectomies). Trainees-assisted operations were associated with longer operative time and shorter hospital stay but no difference in complications rate.

Survey among endocrine surgeons in practice $<7$ years and endocrine surgery fellows. Endocrine surgery fellows performed significantly more endocrine surgery cases in residency than the average graduating GS residents (45 vs 18 thyroidectomies, 26 vs 9 parathyroidectomies, 6 vs 2 neck dissections, 6 vs 2 laparoscopic adrenalectomies, 4 vs 0 pancreatic resections).

The estimated mean number of performed procedures to be competent was 60 thyroidectomies, 50 parathyroidectomies, 15 laparoscopic adrenalectomy, 12 neck dissections, and 12 endocrine pancreas resections. Fellows graduated with a median (range) of 150 (50-300) thyroid, 80 (35-200) parathyroid, 10 $(2-50)$ neck dissection, $13(0-60)$ laparoscopic adrenal, and $3(0-35)$ endocrine pancreas. Fellows felt the least prepared in neck dissection and pancreas.

Between 2004 and 2008, the average endocrine surgery volume of US general surgery and otolaryngology residents increased by approximately $15 \%$ (26.4 to 30.9 cases and 57.1 to 67.3 , respectively). The growth in case volume was mostly from increases in the number of thyroidectomies performed by US general surgery and otolaryngology residents (17.9 to 21.8 and 46.5 to 54.4 , respectively). Overall, there was an increase also in the number of parathyroidectomies ( 8.5 vs 9.1 and 10.6 vs 12.9 , respectively). Most general surgery residents performed thyroidectomies and parathyroidectomies earlier in their training as surgeon juniors. Conversely, otolaryngology residents are performing most thyroidectomies and parathyroidectomies as chief residents. 
Table 3 (continued)

\begin{tabular}{|c|c|c|}
\hline Reference & $\begin{array}{l}\text { Publication } \\
\text { date }\end{array}$ & Main outcomes \\
\hline Monteiro et al. [15] & 2013 & $\begin{array}{l}\text { More thyroid/parathyroid operations are performed with residents in general surgery than ENT; junior residents in } \\
\text { general surgery perform a large percentage of these cases (about } 40 \% \text { ), indicating early exposure to endocrine } \\
\text { surgery and balanced experience between resident levels with minimal effect of fellows. Although junior } \\
\text { residents receive exposure in ENT, a greater proportion is performed by fellows. }\end{array}$ \\
\hline Reinisch et al. [16] & 2016 & $\begin{array}{l}\text { Thyroidectomies performed by residents are not significantly longer and reveal no differences in length of stay or } \\
\text { complication rates. }\end{array}$ \\
\hline Gurrado et al. [17] & 2016 & $\begin{array}{l}\text { Thyroidectomy can be safely performed by residents correctly supervised. Innovative gradual training in } \\
\text { dedicated high-volume hospitals should be proposed in order to allow adequate autonomy for the residents and } \\
\text { safeguard patient outcome. }\end{array}$ \\
\hline Feeney et al. [18] & 2017 & $\begin{array}{l}\text { A total of } 84,711 \text { cases were identified of which } 45 \% \text { involved trainee participation. There was not an increased } \\
\text { overall or neurologic complication odds when a surgical trainee was involved. }\end{array}$ \\
\hline $\begin{array}{l}\text { Kshirsagar et al. } \\
\text { [19] }\end{array}$ & 2017 & $\begin{array}{l}\text { Resident participation in thyroid surgery was not associated with an increased 30-day postoperative complication } \\
\text { rate. }\end{array}$ \\
\hline Folsom et al. [20] & 2017 & $\begin{array}{l}\text { Resident participation in hemithyroidectomy may be associated with increased operative duration, higher } \\
\text { incidence of wound complications, and readmission. }\end{array}$ \\
\hline Feeney et al. [18] & 2017 & $\begin{array}{l}\text { A total of } 84,711 \text { thyroid and parathyroid surgical procedures cases were gathered from the American College of } \\
\text { Surgeons National Surgical Quality Improvement Project database: of them, } 45 \% \text { involved trainee } \\
\text { participation. No difference in the odds of overall patient complications or neurologic complications was } \\
\text { observed when a trainee was involved. Mean operative time was found to be significantly different between } \\
\text { attending only and junior and senior trainees. There was no significant difference in operative time between } \\
\text { fellows and attending only. }\end{array}$ \\
\hline $\begin{array}{l}\text { Phitayakorn et al. } \\
\text { [3] }\end{array}$ & 2017 & $\begin{array}{l}\text { A survey was conducted among members of the AAES. A total of } 92 \% \text { of the respondents operate with residents. } \\
\text { On average, they believed that the steps of a total thyroidectomy for benign disease and a well-localized } \\
\text { parathyroidectomy could be performed by a postgraduate year } 4 \text { surgery resident. Specific steps that they } \\
\text { thought might require more training included decisions to divide the strap muscles or leaving a drain. } \\
\text { Approximately } 66 \% \text { of respondents thought that a postgraduate year } 5 \text { surgery resident could independently } \\
\text { perform a total thyroidectomy for benign disease, but only } 45 \% \text { felt similarly for malignant thyroid disease; } \\
79 \% \text { thought that a postgraduate year } 5 \text { surgery resident could independently perform a parathyroidectomy. }\end{array}$ \\
\hline Kay et al. [21] & 2018 & $\begin{array}{l}\text { The number of endocrine surgeries performed by US otolaryngology residents has steadily grown from } 1029 \text { in } \\
1996 \text { to } 1945 \text { in } 2015 \text {. The most significant growth occurred in endocrine surgery, in which there was a } 288 \% \\
\text { increase from } 18.4 \text { surgeries per resident in } 1996 \text { to } 71.5 \text { surgeries per resident in } 2015 \text {. The mean number of } \\
\text { thyroidectomy surgeries performed by graduating residents increased from } 16.5 \text { in } 1996 \text { to } 55.2 \text { in } 2015 \text { ( } 235 \% \\
\text { increase), and parathyroid surgeries increased from } 2.0 \text { in } 1996 \text { to } 16.3 \text { in } 2015 \text { ( } 715 \% \text { increase). }\end{array}$ \\
\hline
\end{tabular}

of RRC [11]. Fellowship programs provide self-reported estimates on their operative volumes in thyroid, parathyroid, adrenal, neuroendocrine pancreas, and gastrointestinal endocrine procedures [11]. US fellowship programs showed significant differences in the numbers of endocrine operative cases performed at each program ranging from 10 to 500 parathyroidectomies [11]. During the early 2000s, the AAES recognized that endocrine surgery fellows graduated with a median of 80 90 parathyroid procedures (range 35-200) [9, 13] (Table 3). These numbers exceed the estimated numbers of performed cases to be competent (50, range 10-100) [13]. Given the rapid changes in parathyroid surgery over the past decade, in terms of preoperative localization studies, intraoperative PTH monitoring, and focused approaches in localized disease, AAES fellowship programs teach congruent management strategies that include focused dissection for localized disease and four-glands exploration if multiglandular disease is suspected, with intraoperative parathyroid hormone use and the intent to cure patients at the first surgery [22].
Trainees are involved in 45-73\% of endocrine surgical operations performed at hospitals participating in the National Surgical Quality Improvement Program (NSQIP) of the American College of Surgeons [12, 18]. Between 2005 and 2008, senior residents assisted 36.7\%, junior residents $32.9 \%$, and endocrine surgery fellows $8.2 \%$ of 9101 parathyroidectomies [12]. Trainee-assisted operations were usually associated with longer operative time [12], especially if assisted by junior or senior residents $[12,18]$. No difference in complications rate was observed when a trainee was involved [12, 18] (Table 3).

\section{Training in adrenal gland surgery}

\section{Survey results}

There was a poor reply rate to the questions related to adrenal surgery. Only three respondents (from Poland, Slovenia, and Turkey) described their personal experience. Median (range) 
numbers were 5 (3-30) for open adrenalectomies performed, 5 (5-50) for open adrenalectomies assisted, 5 (2-30) for minimally invasive adrenalectomies performed, and $10(5-50)$ for minimally invasive adrenalectomies assisted.

Nine respondents declared their personal views suggesting that during training one should be exposed to a median of 10 (2-30) open adrenalectomies performed and 10 (10-50) assisted and 10 (5-30) minimally invasive adrenalectomies performed and $10(10-50)$ assisted.

The national requirements for becoming a fellow in endocrine surgery varied widely with a median of 10 (5-60) for performed adrenalectomies and 15 (10-100) for assisted adrenalectomies. The national delegates view was that a median of 20 performed and 20 assisted adrenalectomies should be required but once again their views varied widely (range 7-60 and $15-100$, respectively). These figures are well over the workload of many units and reinforce the need to centralize training in adrenal surgery in a small number of units with workload of probably over 20 cases/year.

\section{Literature regarding training in adrenal surgery}

Data published on the current exposure of surgical residents to adrenal surgery is focused mainly on the North American situation but anecdotal evidence from most European countries is very similar. In a survey of 22 graduates from a general surgery residency program, over $50 \%$ did not feel competent performing several operations including adrenalectomy and this was an area considered to be in need of educational improvement at a program level (in addition to other operations such as abdominoperineal resection, transanal excision of tumors, transhiatal esophagectomy, and Whipple operations). Surprisingly, the analysis of their logbooks showed that increased case volume correlated with competence for adrenalectomy at very small numbers (3 vs. 1 ) though no established surgeon would accept that having been involved or having performed three adrenalectomies equates to competence of the procedure [23].

The exposure to small numbers of adrenal procedures has been reported repeatedly over the last decades. A study that examined the operative experience of general surgery residents in endocrine surgery for the academic years 19861987 to $1993-1994$ found this training to be inadequate due to low operative volume. In a review of more recent data from the Resident Statistic Summaries from 1994-1995 to 20032004 , the average number of adrenalectomies per resident was 1.46 (for endocrine pancreas, the average was 0.14 ). The most common number of any of these procedures performed by US graduates was zero [11]. A more recent analysis of case-log data from 2004 to 2009 for American urology residents showed no improvement while for Canadian residents there was a slightly improved exposure [24]
Exposure to endocrine (adrenal) surgery and mentorship during residency programs are powerful factors that influence residents to pursue careers in endocrine surgery. In a recent survey, fellows performed significantly more endocrine surgery cases during residency than the average graduating chief resident and mentorship was a critical factor in fellows' decisions to pursue endocrine surgery. Fellows graduated with a median (range) of $13(0-60)$ laparoscopic adrenal operations (compared with 150 (50-300) thyroid operations) [13]. When questioned about the "ideal" exposure they would aim for about 30. Fellows in minimally invasive surgery (MIS) listed the case volume for adrenalectomy as insufficient (similar to the situation for laparoscopic gastric banding, colectomy, common bile duct exploration, gastrectomy, esophagectomy, splenectomy, hepatectomy, nephrectomy, and pancreatectomy) [25].

It is abundantly clear that adrenalectomy is clearly established on the list of topics for which training remains poor in consecutive generations of trainees.

Impact of involving trainees in adrenal surgery In a retrospective study using the American College of Surgeons National Surgical Quality Improvement Program database of 3219 adrenalectomies (735 open adrenalectomies and 2484 laparoscopic adrenalectomies), residents were involved in 2582 surgeries and senior residents or fellows performed the majority of the cases (85\%). Resident participation led to a longer mean operative time but was not associated with significant differences in the operative outcomes of 30-day mortality or postoperative complications [26]. In contrast with these nationwide results, the operative time was reported to be similar when cases were performed under supervision of a dedicated trainer. In one study, $34 \%$ of the patients were operated by residents and $66 \%$ of the patients by a certified senior surgeon. There were no differences in operation time, intraoperative complications, postoperative complications, and length of stay between the patients operated by senior residents and those by certified surgeons [27].

The benefits of involving trainees in such cases were confirmed in a cohort study of 3694 patients who underwent adrenalectomy identified from the American College of Surgeons NSQIP database. A total of 732 adrenalectomies (20\%) were performed by an attending surgeon with no trainee, $2315(63 \%)$ involved a resident, and $647(17 \%)$ involved a fellow. The participation of fellows was associated with fewer serious complications $(7.9 \%$ with no trainee, $6.0 \%$ with residents, and $2.8 \%$ with fellows; $p<0.001$ ). The odds of serious 30-day morbidity were lower when attending surgeons operated with residents (odds ratio $=0.63 ; 95 \%$ CI, 0.45-0.89). Fellow participation was associated with significantly lower odds of overall (odds ratio $=0.51 ; 95 \%$ CI, 0.32-0.82) and serious (odds ratio $=0.31 ; 95 \% \mathrm{CI}, 0.17-0.57$ ) morbidity. There was no significant association between trainee 
participation and 30-day mortality [28]. The same database was interrogated in another study of adrenal operations performed during 2005-2008 and no significant difference was found concerning the rates of wound infections, medical complications, reoperations, or overall morbidity between cases operated by the attending alone and those with the involvement of fellows/residents [12].

In summary, centers with adequate involvement in adrenal surgery should consider trainees as an integral and beneficial part of the surgical team and patients should feel and be reassured about their outcomes not being compromised.

Evidence of a learning curve for new techniques After the report of laparoscopic adrenalectomy (LA) by Michel Gagner in early 1990s, this operation became the procedure of choice in the surgical management of most adrenal tumors. The "pioneers" never reported/analyzed their personal journey but later several groups aimed to define the learning curve for LA.

In one analysis, the first 100 LA procedures performed were divided into three, equal consecutive groups $(n=33$, 33, and 34). The frequency of intraoperative complications in the intermediate and late group was significantly less compared with that in the early group ( 2 out of 33,2 out of 34 , and 7 out of 33, respectively; $(p<0.05)$. Similarly, the mean operating time was significantly reduced between the early (169 $\mathrm{min})$ and both intermediate $(116 \mathrm{~min})$ and late $(127 \mathrm{~min})$ group $(p<0.005)$. The conversion rate was reduced between the three groups $(3 / 33,2 / 33$, and $0 / 34, p=0.06)$. According to this study, it seems that approximately 30 cases by an experienced laparoscopic surgeon are required to master the procedure [29].

Similar figures were quoted in a study from Italy who found that the operative time and conversion rates flattened their curves roughly at 30 and 40 procedures for right and left LA, respectively [30].

If a surgeon needs 30 cases (or more) before completing a personal learning curve and considering that the vast majority of surgeons performing LA undertake less than 6 cases/year, it would mean that more than 5 years would be needed for this surgeon to pass this learning curve. As such, it is even more concerning to learn that, in the UK, 186 of 222 surgeons involved in adrenal surgery perform less than 6 cases per year with a median of 1 case/year [31]. For this huge cohort of surgeons, their personal learning curve might not be completed during their entire career.

In the last decade, the wider adoption of retroperitoneoscopic adrenalectomy has offered the opportunity to analyze a learning curve for this new technique in centers already familiar with laparoscopic adrenalectomy. Several case series reported the experience of individual surgeons or centers in rather large number of patients (Table 4).

The learning curve is not easy to define based on a set number as local and personal/individual factors might induce significant variability. For example, in a report from four surgical teams from university centers in three different countries who analyzed their first 181 consecutive posterior retroperitoneoscopic adrenalectomies, competency was achieved after a range of 24-42 procedures [36].

Some expect that robotic adrenalectomy (RA) is going to be increasingly adopted in the coming years but currently few centers have embraced this technique as the associated costs do not offset any immediate clinical benefits. There is therefore very limited data to comment on a learning curve for RA. One paper comments on a significant reduction in operative times with gaining experience during exposure to 30 consecutive robot-assisted unilateral transperitoneal adrenalectomy procedures [37].

New/experimental training methods for adrenal surgery It is expected that without formal structure, most units will use a similar model of staged clinical laparoscopic training program (without laboratory trainings) for beginners to perform LA. One paper reported the experience of five beginners with no previous experience in adrenalectomy who were randomly selected to receive the staged clinical laparoscopic training, including open retroperitoneal adrenalectomy or radical nephrectomy and mentor-initiated clinical laparoscopic training. The clinical data of the 15 LAs performed by each the trainees were collected and compared with the data from the initial 15 LAs of the mentor. All LAs were completed successfully, and no procedure required conversion to open surgery. The median operative time of the trainees was obviously shorter than the mentors' time. The learning curve of the trainees was shorter compared with that of the mentor. The perioperative complication rate was similar between trainees and mentor. Beginners without laboratory trainings could perform LA safely and effectively after they participated in staged clinical laparoscopic training [38].

Staged laparoscopic training, including box-trainer, animal model, and mentor-initiated clinical training, was assessed using 5 beginners (postgraduate years 1-5) without previous experience in open adrenalectomy. During the clinical training, the trainees acted as the camera holder first and then selectively performed simple operations or parts. Finally, each of them performed 30 LAs independently under the mentor's supervision using the technique of anatomic retroperitoneoscopic adrenalectomy. The learning curve among the trainees was shorter compared with that of the mentor. The authors concluded that it was safe and feasible for beginners without previous open counterpart experience to perform LA using staged training [39].

A surgeon-authored virtual reality (VR) training module authored by surgeons using the Toolkit for Illustration of Procedures in Surgery (TIPS) has been reported. A specialist surgeon authored the module, including force-feedback interactive simulation, and designed a quiz to test the knowledge of the key procedural steps. Five practicing surgeons, with 15 to 
Table 4 Data published demonstrating the learning curve for retroperitoneoscopic adrenalectomy (RPA)

Reference Total number of Changes in operating times

RPA cases

$\begin{array}{ll}\text { van Uitert et al. [32] } & 113 \\ \text { Cabalag et al. [33] } & 50 \\ \text { Fukumoto et al. [34] } & 103\end{array}$

Barczyński et al. [35] 100

\begin{abstract}
A median of $100 \mathrm{~min}$ in the first 20 patients decreased to $60 \mathrm{~min}$ after 40 patients, $p<0.05$.
Operation time was decreased after 15 cases from 70.5 (54-85) min to median operative time $61 \mathrm{~min}$.

The learning curve stabilized at 30 cases. The cases were divided into two groups, the learning stage (LS) (cases 1-29) and master stage (MS) (cases 30-103) groups. In the LS group, the mean pneumoperitoneum time was $92 \pm 35 \mathrm{~min}$, which was significantly longer than the equivalent value for the MS group ( $55 \pm 18$ $\min , p<0.001)$. In the LS group, the tumor size $(\geq 50 \mathrm{~mm})$ and the visceral fat area (VFA)/total fat area (TFA) ratio $(\geq 0.49)$ were significantly associated with a prolonged pneumoperitoneum time $(p=0.046$ and 0.046 , respectively) (odds ratio 20.83 and 20.83 , respectively). On the other hand, none of these factors were found to be associated with a prolonged pneumoperitoneum time in the MS group.

The steep segment of the learning curve took about 20-25 cases both during the invention phase of the RPA method and implementation phase in a different hospital 10 years later. Operations for pheochromocytoma, adrenal tumors larger than $3 \mathrm{~cm}$ in diameter, and male gender were found to affect the operating time in univariate analysis (mean $18.7 \pm 5.4$ vs $16.5 \pm 4.6$ vs $10.7 \pm 3.2 \mathrm{~min}$, respectively), whereas BMI was not a factor in this respect.
\end{abstract}

24 years of experience, peer reviewed and tested the module. In all, 14 residents and 9 fellows trained with the module and answered the quiz, pre-use and post-use. Participants received an overview during surgical grand rounds session and a 20min one-on-one tutorial followed by $30 \mathrm{~min}$ of instruction in addition to a force-feedback interactive simulation session. Additionally, in answering the questionnaires, the trainees reflected on their learning experience and their experience with the TIPS framework. Correct quiz response rates on procedural steps improved significantly post-use over pre-use. In the questionnaire, $96 \%$ of the respondents stated that the TIPS module prepares them well or very well for the adrenalectomy, and $87 \%$ indicated that the module successfully teaches the steps of the procedure. All participants indicated that they preferred the module compared with training using purely physical props, one-on-one teaching, medical atlases, and video recordings [40, 41].

Mentorship is used when established surgeons embark on learning a new operative technique. One study objectively evaluated the impact of mentorship on the performance of RA and also compared it with LA. After implementing the use of RA, a retrospective review of the operative experience of two high-volume endocrine surgeons was performed. Both surgeons participated in a hands-on RA mentorship. Clinical presentation and perioperative outcomes were compared. Subgroup analysis was used to compare RA pre- and postmentorship with LA. Sixty-one LAs and 31 RAs were included in the analysis. The mean operative time was 115 for LA versus $90 \mathrm{~min}$ for RA $(p=0.002)$. Ten patients were treated by RA in the pre-mentorship era versus 21 in the post-mentorship era. The mean operative time for the pre-mentorship group was $118 \mathrm{~min}$, which decreased to 77 min post-mentorship ( $p$ $<0.0001)$. LOS also decreased from 2.0 to 1.2 days $(p=0.04)$ in the post-mentorship era [42].
Telementoring is a video-conferencing tool which can deliver expert opinion to physicians and their patients in remote locations. We report our experience with the use of telementoring as a technique to instruct in the performance of posterior retroperitoneoscopic adrenalectomy (PRA). Two consecutive PRAs conducted at Yale New Haven Hospital, New Haven, Connecticut, with telementored guidance from MD Anderson Cancer Center, Houston, Texas, were presented in a recent publication. The PRAs were performed after careful preparation of appropriate issues regarding crossinstitutional telementoring. The procedures were performed quickly and safely. Loss of transmission occurred once but was re-established within seconds and was not disruptive to the surgical procedure. Patients were discharged within $48 \mathrm{~h}$ and without complications. In our experience, telementoring was convenient and effective in helping with the execution of a new surgical technique [43].

The same technique of telementoring was used to introduce PRA to Melbourne, Australia, where no highly experienced surgeon-mentors were available. A surgeon with experience of 12 PRA procedures attended from interstate, along with live telementoring via Skype video link by an overseas surgeon who had performed more than 200 PRA procedures, to mentor the surgeon-learner performing her first three cases. The operating surgeon's first three PRA procedures proceeded uneventfully, with no complications, relatively short operative times, and one-night hospital stays for all three patients. It is important that the surgeon-learner has the skills and experience to complete the procedure using alternative techniques in the case of complications or technical failure [44].

Similarly, an Italian group described their experience with laparoscopic telementored adrenalectomy. Eight laparoscopic telementored adrenalectomies were performed between two separate operating sites $430 \mathrm{~km}$ apart. Six of these procedures 
were unilateral laparoscopic adrenalectomies, and one was bilateral. All cases were performed by an expert open surgeon who was skilled in laparoscopic procedure but who had no experience in laparoscopic adrenalectomy. All the procedures were successfully performed in a telementored fashion. The mean operative times, blood loss, and postoperative morbidity results were comparable with those for standard laparoscopic adrenalectomies reported in the literature [45].

\section{Training in surgery on gastro-entero-pancreatic neuroendocrine tumors}

\section{Survey results}

There is a big variety concerning the numbers of operations for gastric, intestinal, and pancreatic procedures in the European countries. When it comes to training of surgical residents, the majority of operations performed on these organs (namely the stomach, the intestine, and the pancreas) are not performed on patients with NETs. This is a big difference as compared with thyroid gland, parathyroid gland, and adrenal gland procedures.

Our survey revealed that surgical residents according to the national surgical boards are required to perform between 0 and 15 gastric operations. However, the median number of required performed procedures was zero. Most national delegates felt that 4 (median) gastric operations should be performed by residents themselves. When asked for assisted gastric operations, the number was only slightly higher. According to the national delegates, 5 (median) operations were considered sufficient.

With regard to intestinal (small and large bowel) procedures, the numbers for required operations according to the national surgical boards were somewhat higher. In some countries, the minimum number of performed procedures was as high as 50 . On average, however, only 5 (median) performed operations were required. The national delegates considered 12.5 (median) performed operations sufficient. Residents were required to assist 9 (median) intestinal operations while 10 (median) operations were considered appropriate by the national delegates.

In contrast to these numbers, pancreatic procedures are rather very rare. While the numbers for required performed (median 0 ) and assisted (median 0 ) operations were very low, slightly higher numbers (performed $n=2$, assisted $n=5$ ) were considered appropriate by the national delegates.

Adding the above numbers of gastric, intestinal, and pancreatic procedures, surgical residents should perform at least about 15 and assist another 15 GEP-NET operations according to the national delegates. The current number of required operations by the DES (performed $n=2$, assisted $n=5$ ) therefore appears very low.
As expected, the numbers considered to be appropriate for endocrine fellows were generally higher. While up to 30 performed and an additional 30 assisted gastric procedures were considered appropriate, the median number of appropriate procedures was 5 for performed and 8 for assisted operations. With regard to intestinal (small and large bowel) procedures, these numbers were slightly higher. The median numbers considered appropriate were 7 for performed and 10 for assisted operations. The median numbers were even relatively high for pancreatic procedures with 5 for performed and 20 for assisted procedures.

While the median numbers of operations considered to be appropriate overall were relatively high, the numbers that are required according to the national surgical boards were quite low in some countries. In addition, surgery of GEP-NETs is not part of a fellowship program in most European countries.

\section{Literature regarding training in GEP-NET}

GEP-NETs are rather rare entities and their surgical treatment is not universally managed. Gastric NET may be surgically treated by general surgeons, upper-gastrointestinal surgeons, and endocrine surgeons. Enteric NETs may be operated on by general surgeons, lower gastrointestinal surgeons, colorectal surgeons, and endocrine surgeons. Pancreatic NETs may be in the same hands as gastric NETs. Since the surgical treatment of these tumors is distributed among various surgical subspecialties, any general statement is difficult to make. It has been shown that defining the right surgical fellowship program can be a challenge in itself [46].

Literature addressing training of surgical residents or fellows with regard to gastro-entero-pancreatic neuroendocrine tumors is almost non-existing. This is somewhat surprising owing to the fact that the surgical strategy on neuroendocrine tumors may differ somewhat from that used in their more common adenocarcinoma counterparts. This applies both to the resection of primary tumors and also to metastases [47]. Thus, there would be a lot to teach. Nevertheless, some literature exists on the training of both residents and fellows with regard to gastric, colorectal, and hepato-pancreato-biliary surgery in general and this will be addressed below. Of course, the procedures analyzed may differ a lot from those used in patients with GEP-NETs but the findings may give some important clues.

Gastric operations With regard to training of gastric operations, many studies address bariatric procedures. It has been shown that a stepwise approach consisting of (1) the creation of the gastric pouch, (2) identification of the ligament of Treitz, measuring the biliopancreatic limb and creating the stapled gastrojejunostomy, (3) laparoscopic suture closure of the linear stapled gastrojejunal anastomosis, (4) measuring the alimentary limb and creating the stapled jejunojejunostomy, 
and (5) laparoscopic suture closure of the linear stapled jejunojejunal anastomosis can teach residents to perform a laparoscopic Roux-en-Y gastric bypass in an efficient and safe way [48]. This was also shown for robotic laparoscopic gastric banding surgery [49]. Animal models have been successfully used to train 1-year residents performing a gastrojejunostomy [50] and for some gastric procedures (e.g., laparoscopic pyloromyotomy), 3D models have been shown to be of help to teach trainees [51].

Some investigators reported that resident participation seems to lead to an increase of the incidence of superficial site infection $[52,53]$ most likely due to longer operating times but this was considered to be clinically insignificant.

When it comes to laparoscopic gastric cancer surgery, it has been stated that the current exposure of trainees might be considered insufficient [54].

Intestinal operations A study from Switzerland showed that less than 5\% of all segmental colectomies between 2006 and 2015 were performed by residents [55]. During the same time period, the annual number of graduates increased by more than $100 \%$. It is therefore not surprising that a low rate of competence and subsequently confidence was found in another study analyzing laparoscopic colorectal surgery [56]. Earlier exposure of surgical residents has been demanded with regard to laparoscopic colorectal surgery [57]. Possible solutions could include video-trainers and animal models [56].

With regard to laparoscopic colorectal surgery, it has been shown that residents during their final years very well can achieve results that do not affect patient safety and short-term outcome adversely [58]. And some authors did not find any difference in intraoperative adverse effects during colonic procedures when comparing consultants with trainees [59].

Obviously, fellows are more likely to be confronted with the required number of operations. A study analyzing independency of fellows performing laparoscopic colorectal procedures showed that it can be achieved but quite a number of procedures (more than 50) may be necessary [60, 61]. Still, it has been shown that surgeons having reached such a competence immediately thereafter can successfully train other colleagues [62]. One challenge is that fellowship programs compete with residence programs. In one study, only a few program directors considered fellow programs having a positive effect on the residence program [63].

Pancreatic operations In 1996, Harness and colleagues published a study from the USA on the experience of residents with regard to some rare endocrine diseases including endocrine pancreatic surgery [64]. Over a timespan from 1986 to 1994 , the maximum number of endocrine pancreatic procedures ranged from 3 to 10 . However, almost $85 \%$ of the residents did not perform any such procedure at all. The authors concluded that most resident graduates have little or no experience with any of these procedures.

A survey sent to program directors of general surgery in the USA to determine how Accreditation Council for Graduate Medical Education (ACGME) hepato-pancreato-biliary (HPB) requirements were met revealed that about one-fourth of the directors were required to send their residents to other facilities in order to be able to offer the required number of operations [63]. While residents completed about $70 \%$ of all operations, less than $50 \%$ were considered competent by the program directors. This may not be surprising, since more than $50 \%$ of all operations by the residents were performed during the final year while less than $50 \%$ were performed during resident years $1-4$ [65]. Residents performed less than 10 pancreas and liver operations giving them practically no chance to become independent and subsequently competent [65]. It would be desirable to expose residents sooner to more complex procedures [66]. For these more complex procedures, a stepwise approach can achieve satisfying results [67]. With regard to training, the usefulness of 3D modelling (pancreas) has been shown [68].

While residents used to complete only very few pancreatic procedures [69], current programs in the USA seem to be able to offer fellows quite sufficient numbers of operations with a median of close to 50 liver cases and more than 60 pancreatic cases [70].

Operations performed by fellows have been shown to be associated with a higher morbidity, in particular due to an increased frequency of infections, while the mortality rate did not differ significantly as compared with experiences surgeons [71, 72].

It has been shown that fellows and residents compete with each other but that residence training in laparoscopic surgery in the absence of fellows may not affect patients' outcome [73]. This is another argument in favor with teaching as early as possible. When the number of cases is high enough, fellows do not negatively affect the training of surgical residents [74].

\section{Discussion}

This study represents the first European survey evaluating the training in endocrine surgical procedures of general surgery/ otolaryngology residents and endocrine surgery fellows. The work was undertaken on the background of a paucity of data regarding training in endocrine surgical procedures outside the USA.

The analysis of the existing literature confirms that the exposure of graduating residents to endocrine surgical procedures is far from what should be considered adequate to achieve individual competency [13] (Table 3) and what is recommended to be eligible for applying for the EBSQ of the DES (Table 1). This is true for thyroid and parathyroid procedures, but is particularly evident for less common and probably more demanding operations, such as GEP-NET resections and lateral neck dissection 
$[11,13,64]$. The only exception could be the US otolaryngology-head and neck-residency programs that in recent years have exposed graduating residents to increasing neck endocrine surgical activities, consistent with the minimum for achieving surgical competency [21]. In addition, nonEuropean endocrine surgeons (USA, Canada, and South Africa) who responded to the present survey, depicted a minimal exposure of general surgery residents to endocrine surgical procedures (less than 5 procedures in most of the cases; data not included in the present analysis).

While it has been extensively demonstrated that involving residents in endocrine surgery procedures is associated with longer operative times, it is not associated with clinically significant increased complication rates $[12,17,18]$. In our opinion, slightly longer operating times are an affordable price to pay in order to obtain adequate resident training. Obviously, resident involvement should be progressive and standardized based on the complexity of the surgical steps and of the surgical procedures [3]. It has been shown that comprehensive surgical coaching comprised performance analysis, debriefing, feedback, and behavior modelling can enhance the results in skill acquisition as compared with conventional training [75].

In addition, the number of procedures performed and assisted represents only a rough tool to evaluate graduating residents' proficiency. Tools to objectively evaluate surgical skill could be useful but they are yet to be validated in current practice [76].

Of note, residents who graduated in programs, in which one or more faculty members were endocrine surgeons, were significantly more exposed and trained in endocrine surgical procedures comparing with the average general surgery residents $[6,13]$. As a consequence, one should argue that the numbers reported for endocrine surgical activity during residency from the present survey could be overestimated. Indeed, this is not a report based on official data of residents' surgery case logs obtained from official institutions (which, to our knowledge, do not exist for most of the European countries) but based on self-estimated reports of the national delegates of the DES/ESES. By definition, all the respondents are active "endocrine surgeons" and could be influenced by their own experience. Obviously, this could be considered the main limitation of the present evaluation.

It is evident that general surgery specialists who apply for endocrine surgery fellowships during residency were more exposed and trained in endocrine surgical procedures [13]. This underlines the importance of mentorship and tutorship during the training of future surgeons. Exposure starts during medical school and medical students during their surgical rotations are probably underexposed to endocrine surgery, even those who will opt for surgical residency [77]. Since this paucity of exposure may have significant detrimental educational and career ramifications, it would be expected and suggested that endocrine surgeons, especially those who are involved in academic and tutoring activities, would be more active in exposing medical students and resident to endocrine surgery procedures. This is in line with the results of the current survey, since the vast majority, if not all, of the respondents expected and advocated an increase in the exposure of surgical residents to endocrine surgery procedures, both as assistant and as performing surgeon.

Considering the usually inadequate endocrine surgical training during residency, surgery residents wishing to practice endocrine surgery may benefit from additional training in their final year or dedicated fellowship training [14]. Many studies published in recent years showed a relationship between hospital/surgeon volume and patient outcomes which highlights the importance of advanced postgraduate training in endocrine surgery [78-83]. Two years of additional fellowship training in thyroid and endocrine surgery is now being advocated by an increasing number of national endocrine surgical associations as the best way to prepare surgeons for society's needs for highly skilled, competent thyroid surgeons of the future [1]. Indeed, recognized endocrine surgery fellowships seem to provide the necessary additional surgical experience $[9,11,13]$ and are usually able also to give competence on concepts and approaches, which are relevant in the modern endocrine surgical practice, including minimally invasive techniques and intraoperative adjuncts (i.e., IOPTH monitoring, IONM, etc.) $[22,84]$. However, graduated fellows do not feel prepared and competent in all the surgical procedures they could be faced with in individual practice, especially regarding those procedures that are less common and, presumably, more complex, including pancreatic resection and neck dissection [13].

In addition, there is a wide discrepancy in different endocrine surgery fellowship programs, both at national and international levels. This is evident from the analysis of the pertinent literature (which, of note, considered only the endocrine surgery fellowship programs recognized by the IAES or the AAES) and from the present survey. Not all graduated endocrine surgery fellows are trained in the same way and with the same objectives and curricula.

Due to the paucity of recognized fellowship programs and to the heterogeneity of the existing ones, an implementation and standardization of fellowship programs could be advocated at national and/or international levels. It has been noted many years ago that the surgeon plays an important prognostic factor in endocrine surgical diseases [85]. Therefore, proper training of the "successors" should be in the main interest of every practicing surgeon involved in endocrine surgery. As much as one is responsible for the good outcome of the care of current patients, one is equally responsible for the training of those who will take care of future patients.

The survey clearly showed that most of the current numbers of performed and assisted operations required to be eligible to be examined by the DES are comparable with what European national surgical boards have defined and what 
European national delegates consider to be appropriate (Fig. 1a). However, some of the current numbers as defined by the DES are far below what both European national surgical boards and national delegates do recommend. The DES requires only 2 performed central and lateral lymph node dissections each. This is far beyond what national surgical boards and national delegates recommend. Between 10 and 15 performed central and lateral lymph node dissections appear to be more appropriate (Fig. 1e, g).

Established surgeons with a practice in adrenal surgery should have a minimum workload of 6 cases/year. When this cannot be secured, referral to alternative medical centers or centralization of practice should be compulsory. In view of a recognized learning curve for new techniques, retroperitoneoscopic adrenalectomy should be adopted in centers with a minimum of $12-20$ cases/year. Training in robotic adrenal surgery should be provided in the context of a larger expertise in robotic surgery and in centers with annual workload of $>20$ adrenal cases.

Based on national differences in service provision, patients with GEP-NETs should be cared by in centers with a minimum of 10-20 cases per year and trainees with a specific interest in this type of (rare) pathology work in such recognized centers.

However, it is important to underline that operating numbers often are used as an indicator for surgical experience of trainees despite the fact that it has been demonstrated that there is no evidence in any surgical specialty that thresholds of operative experience are equivalent to a particular level of ability [86]. Competence in a certain surgical subspecialty should be regarded as the combination of detailed basic and clinical knowledge and reasoning and clinical and surgical experience. Consequently, although the demonstration of operative experience would seem to be a reliable criterion for evaluating competence in endocrine surgery practice, probably more efficient methods of achieving and evaluating competence would be necessary.

Of note, EBSQ examination for endocrine (neck) surgery qualification evaluates not only surgical experience, based on operative $\log$ book of candidates, but also basic knowledge and clinical reasoning. As a summary of these findings, the authors have formulated a set of statements (Table 5) that were discussed during a plenary session of the ESES 2019 meeting.

\section{Conclusion}

Surgical trainees with an interest in endocrine surgery should work on a unit with a recognized interest in this specialty so that appropriate clinical exposure can be secured. They should aim to obtain formal certification of training through their national examination and/or the DES examination.

Fellowships in endocrine surgery should be available only in large regional centers where multidisciplinary approach to
Table 5 Statements regarding the training of fellows in (neck) endocrine surgery

(a) Training in endocrine surgery should be performed in units that perform a minimum of 100 thyroid, 50 parathyroid, 15 adrenal, and/or 10 GEP-NET operations yearly.

(b) Fellowships of 1-2 years are recommended part of postgraduate training for those who intend to specialize in endocrine surgery.

(c) Fellows should be expected to have been main operator in a minimum of 50 thyroid operation, 10 (central or lateral) lymph node dissections, 15 parathyroid, 5 adrenal, and 5 GEP-NET operations.

(d) Fellows are encouraged to be examined on the national or European level.

(e) The European Society of Endocrine Surgeons (ESES) will support trainees with a dedicated interest by providing the JF Henry Travelling Fellowship.

complex endocrine cases would offer the trainees the best chance for learning a comprehensive management of endocrine surgical diseases.

Acknowledgments The authors thank all national delegates of the DES/ ESES and Janice Pasieka, Herbert Chen, and Jennifer Brown for their participation in the survey.

Authors' contributions - Study conception and design: OG, MB, RM, MR

- Acquisition of data: OG, MB, RM, MR

- Analysis and interpretation of data: OG, MB, RM, MR

- Drafting of manuscript: OG, MB, RM, MR

- Critical revision of manuscript: OG, MB, RM, MR

Funding Information Open access funding provided by Linköping University.

\section{Compliance with ethical standards}

Conflict of interest The authors declare that they have no conflict of interest.

Ethical approval This article does not contain any studies with human participants performed by any of the authors.

Open Access This article is distributed under the terms of the Creative Commons Attribution 4.0 International License (http:// creativecommons.org/licenses/by/4.0/), which permits unrestricted use, distribution, and reproduction in any medium, provided you give appropriate credit to the original author(s) and the source, provide a link to the Creative Commons license, and indicate if changes were made.

\section{References}

1. Harness JK, van Heerden JA, Lennquist S et al (2000) Future of thyroid surgery and training surgeons to meet the expectations of 2000 and beyond. World J Surg 24:976-982

2. Reeve TS, Curtin A, Fingleton L et al (1994) Can total thyroidectomy be performed as safely by general surgeons in provincial centers as by surgeons in specialized endocrine surgical units? Making the case for surgical training. Arch Surg 129:834-836 
3. Phitayakorn R, Kelz RR, Petrusa E et al (2017) Expert consensus of general surgery residents' proficiency with common endocrine operations. Surgery 161:280-288

4. Libutti SK (2010) Endocrine surgery specialty training: opportunities for growth. Surgery 148:1073-1074

5. Harness JK, Organ CH Jr, Thompson NW (1995) Operative experience of U.S. general surgery residents in thyroid and parathyroid disease. Surgery 118:1063-1069 discussion 1069-1070

6. Prinz RA (1996) Endocrine surgical training-some ABC measures. Surgery 120:905-912

7. Parsa CJ, Organ CH Jr, Barkan H (2000) Changing patterns of resident operative experience from 1990 to 1997. Arch Surg 135: 570-573 discussion 573-575

8. Manolidis S, Takashima M, Kirby M et al (2001) Thyroid surgery: a comparison of outcomes between experts and surgeons in training. Otolaryngol Head Neck Surg 125:30-33

9. Sosa JA, Wang TS, Yeo HL et al (2007) The maturation of a specialty: workforce projections for endocrine surgery. Surgery 142 : 876-883

10. Terris DJ, Chen N, Seybt MW et al (2007) Emerging trends in the performance of parathyroid surgery. Laryngoscope 117:1009-1012

11. Le D, Karmali S, Harness JK et al (2008) An update: the operative experience in adrenal, pancreatic, and other less common endocrine diseases of U.S. general surgery residents. World J Surg 32:232236

12. Goldfarb M, Gondek S, Hodin R et al (2010) Resident/fellow assistance in the operating room for endocrine surgery in the era of fellowships. Surgery 148:1065-1071 discussion 1071-1062

13. Solorzano CC, Sosa JA, Lechner SC et al (2010) Endocrine surgery: where are we today? A national survey of young endocrine surgeons. Surgery 147:536-541

14. Zarebczan B, McDonald R, Rajamanickam V et al (2010) Training our future endocrine surgeons: a look at the endocrine surgery operative experience of U.S. surgical residents. Surgery 148:10751080 discussion 1080-1071

15. Monteiro R, Mino JS, Siperstein AE (2013) Trends and disparities in education between specialties in thyroid and parathyroid surgery: an analysis of 55,402 NSQIP patients. Surgery 154:720-728 discussion 728-729

16. Reinisch A, Malkomes P, Liese J et al (2016) Education in thyroid surgery: a matched-pair analysis comparing residents and boardcertified surgeons. Langenbecks Arch Surg 401:239-247

17. Gurrado A, Bellantone R, Cavallaro G et al (2016) Can total thyroidectomy be safely performed by residents?: a comparative retrospective multicenter study. Medicine (Baltimore) 95:e3241

18. Feeney T, Price LL, Chen L et al (2017) Resident and fellow participation in thyroid and parathyroid surgery: an ACS-NSQIP clinical outcomes analysis. J Surg Res 220:346-352

19. Kshirsagar RS, Chandy Z, Mahboubi $\mathrm{H}$ et al (2017) Does resident involvement in thyroid surgery lead to increased postoperative complications? Laryngoscope 127:1242-1246

20. Folsom C, Serbousek K, Lydiatt W et al (2017) Impact of resident training on operative time and safety in hemithyroidectomy. Head Neck 39:1212-1217

21. Kay S, Miller R, Kraus D et al (2018) Evolving phenotype of the head and neck surgeon. Laryngoscope

22. Wang TS, Pasieka JL, Carty SE (2014) Techniques of parathyroid exploration at North American endocrine surgery fellowship programs: what the next generation is being taught. Am J Surg 207: $527-532$

23. Fronza JS, Prystowsky JP, DaRosa D et al (2012) Surgical residents' perception of competence and relevance of the clinical curriculum to future practice. J Surg Educ 69:792-797

24. Hoag NA, Mamut A, Afshar K et al (2012) Trends in urology resident exposure to minimally invasive surgery for index procedures: a tale of two countries. J Surg Educ 69:670-675
25. Tichansky DS, Taddeucci RJ, Harper J et al (2008) Minimally invasive surgery fellows would perform a wider variety of cases in their "ideal" fellowship. Surg Endosc 22:650-654

26. Venkat R, Valdivia PL, Guerrero MA (2014) Resident participation and postoperative outcomes in adrenal surgery. J Surg Res 190:559-564

27. Horesh N, Jacoby H, Dreznik Y et al (2016) Teaching laparoscopic adrenalectomy to surgical residents. J Laparoendosc Adv Surg Tech A 26:453-456

28. Seib CD, Greenblatt DY, Campbell MJ et al (2014) Adrenalectomy outcomes are superior with the participation of residents and fellows. J Am Coll Surg 219:53-60

29. Goitein D, Mintz Y, Gross D et al (2004) Laparoscopic adrenalectomy: ascending the learning curve. Surg Endosc 18:771-773

30. Guerrieri M, Campagnacci R, De Sanctis A et al (2008) The learning curve in laparoscopic adrenalectomy. J Endocrinol Invest 31: 531-536

31. Palazzo F, Dickinson A, Phillips B et al (2016) Adrenal surgery in England: better outcomes in high-volume practices. Clin Endocrinol (Oxf) 85:17-20

32. van Uitert A, d'Ancona FCH, Deinum J et al (2017) Evaluating the learning curve for retroperitoneoscopic adrenalectomy in a highvolume center for laparoscopic adrenal surgery. Surg Endosc 31: 2771-2775

33. Cabalag MS, Mann GB, Gorelik A et al (2015) Posterior retroperitoneoscopic adrenalectomy: outcomes and lessons learned from initial 50 cases. ANZ J Surg 85:478-482

34. Fukumoto K, Miyajima A, Hattori S et al (2017) The learning curve of laparoendoscopic single-site adrenalectomy: an analysis of over 100 cases. Surg Endosc 31:170-177

35. Barczynski M, Konturek A, Golkowski F et al (2007) Posterior retroperitoneoscopic adrenalectomy: a comparison between the initial experience in the invention phase and introductory phase of the new surgical technique. World J Surg 31:65-71

36. Vrielink OM, Engelsman AF, Hemmer PHJ et al (2018) Multicentre study evaluating the surgical learning curve for posterior retroperitoneoscopic adrenalectomy. Br J Surg 105:544-551

37. D'Annibale A, Lucandri G, Monsellato I et al (2012) Robotic adrenalectomy: technical aspects, early results and learning curve. Int J Med Robot 8:483-490

38. Yang Q, Du J, Zhao ZH et al (2013) Is laboratory training essential for beginners in learning laparoscopic adrenalectomy? Surg Laparosc Endosc Percutan Tech 23:184-188

39. Zhang X, Wang B, Ma X et al (2009) Laparoscopic adrenalectomy for beginners without open counterpart experience: initial results under staged training. Urology 73:1061-1065

40. Kurenov S, Cendan J, Dindar S et al (2017) Surgeon-authored virtual laparoscopic adrenalectomy module is judged effective and preferred over traditional teaching tools. Surg Innov 24:72-81

41. Cendan J, Kim M, Kurenov S et al (2007) Developing a multimedia environment for customized teaching of an adrenalectomy. Surg Endosc 21:1012-1016

42. Broome JT, Solorzano CC (2013) Impact of surgical mentorship on retroperitoneoscopic adrenalectomy with comparison to transperitoneal laparoscopic adrenalectomy. Am Surg 79:162-166

43. Treter S, Perrier N, Sosa JA et al (2013) Telementoring: a multiinstitutional experience with the introduction of a novel surgical approach for adrenalectomy. Ann Surg Oncol 20:2754-2758

44. Miller JA, Kwon DS, Dkeidek A et al (2012) Safe introduction of a new surgical technique: remote telementoring for posterior retroperitoneoscopic adrenalectomy. ANZ J Surg 82:813-816

45. Bruschi M, Micali S, Porpiglia F et al (2005) Laparoscopic telementored adrenalectomy: the Italian experience. Surg Endosc $19: 836-840$

46. Rassadi R, Dickerman RM, Dunn EL et al (2008) Hepatopancreaticobiliary (HPB) surgery: what is the right fellowship for the right training? J Surg Educ 65:186-190 
47. Nagorney DM (2014) Ask the experts: management of hepatic metastases from neuroendocrine cancer. Hepat Oncol 1:177-180

48. Walinga AB, van Mil SR, Biter LU et al (2018) A stepwise approach in learning surgical residents a Roux-en-Y gastric bypass. Obes Surg

49. Hashimoto DA, Gomez ED, Danzer E et al (2012) Intraoperative resident education for robotic laparoscopic gastric banding surgery: a pilot study on the safety of stepwise education. J Am Coll Surg 214:990-996

50. Miyasaka KW, Buchholz J, LaMarra D et al (2015) Development and implementation of a clinical pathway approach to simulationbased training for foregut surgery. J Surg Educ 72:625-635

51. Williams A, McWilliam M, Ahlin J et al (2018) A simulated training model for laparoscopic pyloromyotomy: is $3 \mathrm{D}$ printing the way of the future? J Pediatr Surg 53:937-941

52. Doyon L, Moreno-Koehler A, Ricciardi R et al (2016) Resident participation in laparoscopic Roux-en-Y gastric bypass: a comparison of outcomes from the ACS-NSQIP database. Surg Endosc 30: 3216-3224

53. Krell RW, Birkmeyer NJ, Reames BN et al (2014) Effects of resident involvement on complication rates after laparoscopic gastric bypass. J Am Coll Surg 218:253-260

54. Fecso AB, Bonrath EM, Grantcharov TP (2016) Training in laparoscopic gastric cancer surgery in the western world: current educational practices, challenges, and potential opportunities at a large university centre. J Surg Educ 73:749-755

55. Kaser SA, Rickenbacher A, Cabalzar-Wondberg D et al (2018) The growing discrepancy between resident training in colonic surgery and the rising number of general surgery graduates. Int J Colorectal Dis

56. La Torre M, Caruso C (2012) Resident training in laparoscopic colorectal surgery: role of the porcine model. World J Surg 36: 2015-2020

57. Gorgun E, Benlice C, Corrao E et al (2014) Outcomes associated with resident involvement in laparoscopic colorectal surgery suggest a need for earlier and more intensive resident training. Surgery $156: 825-832$

58. Nijhof HW, Silvis R, Vuylsteke R et al (2017) Training residents in laparoscopic colorectal surgery: is supervised surgery safe? Surg Endosc 31:2602-2606

59. Pache B, Grass F, Fournier N et al (2018) Surgical teaching does not increase the risk of intraoperative adverse events. Int $\mathrm{J}$ Colorectal Dis 33:1715-1722

60. Kim JH, Lee IK, Kang WK et al (2013) Initial experience of a surgical fellow in laparoscopic colorectal cancer surgery under training protocol and supervision: comparison of short-term results for 70 early cases (under supervision) and 73 late cases (without supervision). Surg Endosc 27:2900-2906

61. Akiyoshi T, Kuroyanagi H, Ueno M et al (2011) Learning curve for standardized laparoscopic surgery for colorectal cancer under supervision: a single-center experience. Surg Endosc 25:1409-1414

62. McArthur DR, Sharples A, Ghallab M et al (2012) Laparoscopic fellowship training can deliver a competent laparoscopic surgeon and trainer. Colorectal Dis 14:497-501

63. Smithson L, Delvecchio K, Mittal VK (2015) Accreditation Council for Graduate Medical Education compliance and resident competence in hepatopancreaticobiliary surgery during general surgery residency: a program director review. J Surg Educ 72:818-822

64. Harness JK, Organ CH Jr, Thompson NW (1996) Operative experience of U.S. general surgery residents with diseases of the adrenal glands, endocrine pancreas, and other less common endocrine organs. World J Surg 20:885-890 discussion 890-881

65. Sachs TE, Ejaz A, Weiss M et al (2014) Assessing the experience in complex hepatopancreatobiliary surgery among graduating chief residents: is the operative experience enough? Surgery 156:385-393

66. Relles DM, Burkhart RA, Pucci MJ et al (2014) Does resident experience affect outcomes in complex abdominal surgery?
Pancreaticoduodenectomy as an example. J Gastrointest Surg 18: 279-285 discussion 285

67. Sumida Y, Nanashima A, Abo T et al (2010) Stepwise education for pancreaticoduodenectomy for young surgeons at a single Japanese institute. Hepatogastroenterology 57:1046-1051

68. Andolfi C, Plana A, Kania P et al (2017) Usefulness of threedimensional modeling in surgical planning, resident training, and patient education. J Laparoendosc Adv Surg Tech A 27:512-515

69. Helling TS, Khandelwal A (2008) The challenges of resident training in complex hepatic, pancreatic, and biliary procedures. $\mathrm{J}$ Gastrointest Surg 12:153-158

70. Jeyarajah DR, Patel S, Osman H (2015) The current state of hepatopancreatobiliary fellowship experience in North America. J Surg Educ 72:144-147

71. Castleberry AW, Clary BM, Migaly J et al (2013) Resident education in the era of patient safety: a nationwide analysis of outcomes and complications in resident-assisted oncologic surgery. Ann Surg Oncol 20:3715-3724

72. Ejaz A, Spolverato G, Kim Y et al (2015) The impact of resident involvement on surgical outcomes among patients undergoing hepatic and pancreatic resections. Surgery 158:323-330

73. Linn JG, Hungness ES, Clark S et al (2011) General surgery training without laparoscopic surgery fellows: the impact on residents and patients. Surgery 150:752-758

74. Hallowell PT, Dahman MI, Stokes JB et al (2013) Minimally invasive surgery fellowship does not adversely affect general surgery resident case volume: a decade of experience. Am J Surg 205:307311 discussion 311

75. Bonrath EM, Dedy NJ, Gordon LE et al (2015) Comprehensive surgical coaching enhances surgical skill in the operating room: a randomized controlled trial. Ann Surg 262:205-212

76. Larson JL, Williams RG, Ketchum J et al (2005) Feasibility, reliability and validity of an operative performance rating system for evaluating surgery residents. Surgery 138:640-647 discussion 647-649

77. Chen H, Hardacre JM, Martin C et al (2002) Do future general surgery residents have adequate exposure to endocrine surgery during medical school? World J Surg 26:17-21

78. Thompson NW (1996) The evolution of endocrine surgery as a subspecialty of general surgery. Fragmentation or enhancement? Arch Surg 131:465-471

79. Wang TS (2011) Endocrine surgery. Am J Surg 202:369-371

80. Krishnamurthy VD, Jin J, Siperstein A et al (2016) Mapping endocrine surgery: workforce analysis from the last six decades. Surgery 159:102-110

81. Adam MA, Thomas S, Youngwirth L et al (2017) Is there a minimum number of thyroidectomies a surgeon should perform to optimize patient outcomes? Ann Surg 265:402-407

82. Meltzer C, Klau M, Gurushanthaiah D et al (2016) Surgeon volume in thyroid surgery: surgical efficiency, outcomes, and utilization. Laryngoscope 126:2630-2639

83. Nouraei SA, Virk JS, Middleton SE et al (2017) A national analysis of trends, outcomes and volume-outcome relationships in thyroid surgery. Clin Otolaryngol 42:354-365

84. Marti JL, Holm T, Randolph G (2016) Universal use of intraoperative nerve monitoring by recently fellowship-trained thyroid surgeons is common, associated with higher surgical volume, and impacts intraoperative decision-making. World J Surg 40:337-343

85. Pasieka JL (2000) The surgeon as a prognostic factor in endocrine surgical diseases. Surg Oncol Clin N Am 9:13-20 v-vi

86. De Siqueira JR, Gough MJ (2016) Correlation between experience targets and competence for general surgery certification. Br J Surg 103:921-927

Publisher's note Springer Nature remains neutral with regard to jurisdictional claims in published maps and institutional affiliations. 